\title{
Identifying Active Structures Using Double-Difference Earthquake Relocations in Southwest British Columbia and
} the San Juan Islands, Washington

\author{
by Natalie J. Balfour, John F. Cassidy, ${ }^{\dagger}$ and Stan E. Dosso
}

\begin{abstract}
This paper applies double-difference earthquake relocation techniques to investigate sources of seismicity in southwest British Columbia, Canada, and the San Juan Islands, Washington. The study area is a complex region of deformation and has the potential for large earthquakes in the North Americancrust. Double-difference earthquake relocation techniques are applied to identify otherwise-hidden active structures that may pose a hazard to nearby population and infrastructure. We present evidence for previously unrecognized active structures using precise relative earthquake relocations obtained using both catalog and waveform cross-correlation data. Results have significantly reduced errors over routine catalog locations and show lineations in areas of clustered seismicity. In southwest British Columbia, these lineations or streaks appear to be hidden structures that do not disrupt near-surface sediments; however, in the San Juan Islands the identified lineation could be related to recently mapped surface expressions of faults identified from seismic reflection and multibeam bathymetric surveys. We use a variety of velocity models for the relocations and find that inappropriate models lead to artifacts at layer boundaries and increased vertical errors.
\end{abstract}

\section{Introduction}

Southwest British Columbia and northern Washington are located in northern Cascadia where the Juan de Fuca plate is subducting beneath the North American plate. Previous studies have shown this to be a complex region of deformation located above a bend in the subducting plate (Fig. 1; Clowes et al., 1987; Ramachandran et al., 2004; Ristau et al., 2007). This is a region of complex crustal structure as the crust is composed of terranes of accreted island arcs (Monger et al., 1982). There are also many mapped surface faults, some of which mark the boundaries between terranes (Fig. 2).

The Cascadia subduction zone in southwest British Columbia and Washington experiences three types of earthquakes: megathrust earthquakes at the subduction interface, deep earthquakes in the subducting slab, and shallow earthquakes from faults in the overlying crust. These shallow crustal earthquakes, with recorded magnitudes of up to 7.3, pose significant hazard to major population centers in the area, such as Vancouver, Victoria, and Seattle. The largest known crustal earthquake $\left(M_{\mathrm{s}} 7.3\right)$ occurred in 1946 near Courtney on Vancouver Island and caused chimneys and building fronts

\footnotetext{
*Now at Research School of Earth Sciences, The Australian National University, Bldg 61 Mills Road Acton ACT, 0200 Australia.

${ }^{\dagger}$ Also at School of Earth and Ocean Sciences, University of Victoria.
}

to collapse, other structural damage, slumping, and landslides (Rogers and Hasegawa, 1978).

This study seeks to identify and map unknown active structures that might have the potential to cause large crustal earthquakes near urban centers. We chose two regions to investigate in detail (outlined in Figs. 1 and 2). The first is the Fraser River Valley in southwest British Columbia (box 1 in Fig. 2), which was chosen because of the potential risk to infrastructure, such as dams, and its close proximity to greater Vancouver ( 20 km). The second is the San Juan Islands (box 2 in Fig. 2) because of its high seismicity and proximity to Vancouver $(80 \mathrm{~km})$ and Victoria $(30 \mathrm{~km})$.

The vast majority of the seismicity in southwest British Columbia does not relate to surface fault expressions (Fig. 2); hence, it is necessary to use methods that identify otherwisehidden structures. We use the double-difference technique developed by Waldhauser and Ellsworth (2000) for earthquake relocation to search for evidence of unmapped active structures at depth. This precise method for relocating earthquakes relative to one another uses differences in the travel times for closely spaced events. It illuminates the extent of structures with high seismicity and may relate this to the area of possible rupture during an earthquake. This will potentially help identify regions and communities that may be affected by earthquakes on these structures. 


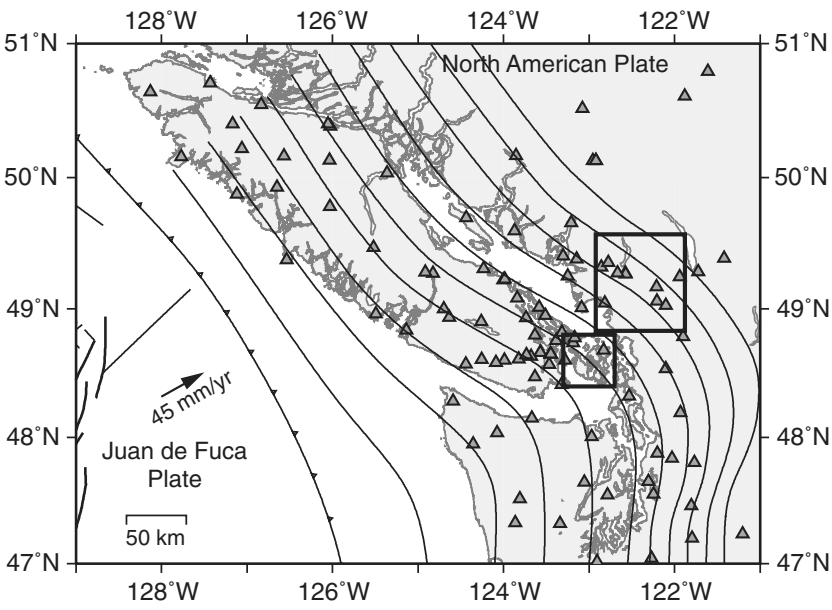

Figure 1. Southwest British Columbia and northwest Washington state. The Fraser River Valley (upper) and San Juan Islands (lower) study regions are outlined by boxes. Stations (triangles) include stations from the Canadian National Seismograph Network (CNSN), Portable Observatories for Lithospheric Analysis and Research Investigating Seismicity (POLARIS), and the Pacific Northwest Seismic Network (PNSN). The approximate location of the Cascadia subduction zone plate boundary and depth contours of the Juan de Fuca plate (McCrory et al. 2004) are shown. The Juan de Fuca plate subducts beneath the North American Plate at $\sim 45 \mathrm{~mm} / \mathrm{yr}$ (Riddihough, 1984).

The double-difference technique has been used in this region by Cassidy et al. (2000) to investigate a sequence of events in the Georgia Strait related to a magnitude $M_{\mathrm{L}} 4.6$ mainshock. They were able to identify a lineation from the aftershock sequence and relate it to the source mechanism of the main event to determine the fault on which the earthquake sequence occurred. In a similar manner, we seek to determine new active structures from microseismicity rather

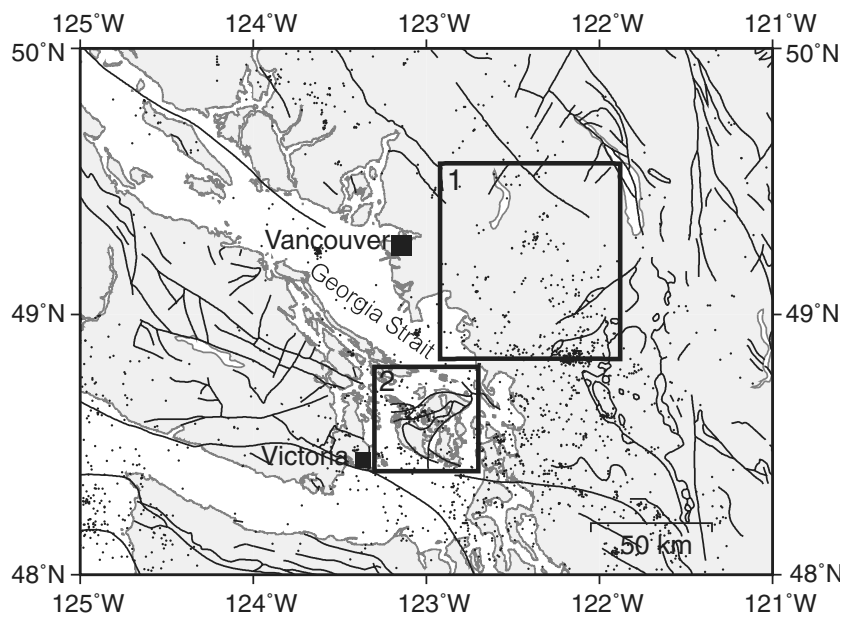

Figure 2. CNSN catalog seismicity from 1970-2011, $M>1.5$, depth $<40 \mathrm{~km}$ (dots) and mapped faults (thin black lines) (Journeay and Williams 1995) in southwest British Columbia and northwest Washington state. Boxes 1 and 2, respectively, outline the Fraser River Valley and the San Juan Islands regions that are discussed in this study. than focus on relocating aftershock sequences to find structures.

\section{Double-Difference Relocation}

The method used here for relocating earthquake hypocenters is a double-difference algorithm known as hypoDD (Waldhauser and Ellsworth, 2000), which solves for event hypocenters and origin times using differential travel-time data from catalog phase picks and/or waveform cross correlations. It does so by minimizing the residuals between the observed and theoretical travel times (double differences) for pairs of earthquakes by adjusting the vector difference between the hypocenters. The relocated hypocenters are determined by solving the double-difference equation for all hypocentral pairs at all stations. A benefit of this method is that it considers the difference between closely space events and therefore reduces the error from unmodeled velocity variations between the station and the event pair.

Relocating events with hypoDD results in precise relative locations and reduces error between events. This may illuminate faults if events are located on the same structure. Results from both synthetic-data and real-data studies show that relative errors are reduced by a factor of $\sim 2$ using catalog arrival times alone and are reduced by a further factor of 2-10 if cross-correlation data are also used (Waldhauser and Ellsworth, 2000; Hauksson and Shearer, 2005).

There are two options to solve the inversion problem, depending on the size on the dataset. The preferred option is to use weighted least squares inversion by applying singular value decomposition (SVD) as this approach quantifies errors in the solution. However, SVD is only applicable to small sets of data ( $<100$ events) because it is computationally intensive. The other option, applicable to larger datasets, is the least squares conjugate gradients method (LSQR; Paige and Saunders, 1982a,b), which does not resolve the errors in the solution. In this case, Waldhauser and Ellsworth (2000) suggest performing a separate analysis on a subset of the data using the SVD or statistical resampling techniques to estimate the uncertainties.

The LSQR approach is used to relocate earthquakes in this study due to the large datasets; therefore, we must evaluate errors using another method. For both regions in this study, we relocated a subset of events using the SVD mode of hypoDD for reliable error estimates. Throughout the results discussion, we report all errors in location as the standard error $(2 \sigma)$.

\section{Catalog Arrival Times}

To apply double-difference relocation to catalog arrival times requires preprocessing of data to calculate the differential travel times for event pairs. We use the program ph2dt (Waldhauser, 2001) to find event pairs by determining a specified number of closely spaced neighbors within a set region that are linked with common stations and phase arrival data. 
For the data in this study, we use a maximum event-to-station distance of $500 \mathrm{~km}$, maximum separation between event pairs of $10 \mathrm{~km}$, and a minimum number of eight links per event pair. We allow for a different maximum number of neighbors depending on the size of the region and the density of seismicity (maximum 15 neighbors for large regions and 10 for small regions).

Further data selection is carried out within hypoDD, which divides events into clusters of related events. This process often reduces the number of events to be relocated because some events may not be strongly related to any other events. Clusters of well-connected events are defined when a group of events is not linked or is weakly linked with any other group. The double-difference algorithm is then applied separately to each cluster. When using only catalog data, two sets of five iterations were performed on each cluster. The first set weights the data based on the a priori weighting from the catalog and weights $P$-wave arrivals higher than $S$-wave arrivals. The a priori weight is defined by the uncertainty in the pick as provided by the analyst (if that information is unavailable, we assume a pick uncertainty of $0.1 \mathrm{~s}$ ). The pick uncertainty is then translated to a weight: an uncertainty of $0-0.1 \mathrm{~s}$ has a weight of 1 ; between $0.1-0.5 \mathrm{~s}$ has a weight of 0.8 ; between $0.5-1 \mathrm{~s}$ has a weight of 0.5 ; and greater than $1 \mathrm{~s}$ has a weight of zero (i.e., the pick is not used). The second iteration down-weights event pairs that have large separations and differential times with high residuals. The parameters for this second iteration vary depending on the density of the data. If the LSQR method is used, then we also define a damping factor to prevent the solution from becoming unstable. The damping factor is chosen by trial and error such that the solution has a condition number between 40-80, as discussed in Waldhauser (2001). Sometimes events are discarded from the relocation during the process due to either being located above the surface or not being linked with any other events.

\section{Waveform Cross Correlation}

Waveform cross-correlation is used on the San Juan Island events to obtain very accurate arrival times and therefore differential arrival times for use in hypoDD. Waveforms from two closely spaced events recorded at the same station are cross-correlated by shifting one waveform past the other in small time increments. The correlation function is the normalized correlation coefficient at each time shift and describes how well the waveforms are correlated: 1 is perfect correlation, 0 is no correlation, and -1 is perfect anticorrelation (waveforms are identical with a polarity reversal). The lag or time shift between two waveforms at maximum correlation indicates the difference in their travel times. Before cross-correlating waveforms, they are filtered using a $1-10-\mathrm{Hz}$ Butterworth filter. The vertical component is used for correlating $P$-wave arrivals, and the east-oriented horizontal component is used for correlating $S$-wave arrivals. When processing events, we save information for pairs of waveforms where the maximum correlation coefficient is $\geq$ 0.7 and the lag is $<0.2 \mathrm{~s}$. Figure 3 shows waveforms for $P$ and $S$ arrivals from events located near the San Juan Islands and recorded at station PGC that meet these criteria. In this figure, the $S$ waves are more highly correlated than the $P$ waves. There is no obvious reason for this; however, in this area very clear $S$-wave arrivals are observed, which may contribute to better correlations due to the higher signal-to-noise ratio. Cross-correlation information is incorporated into hypoDD by using the precise differential arrival times weighted according to the cross-correlation coefficient (squared coherency to include negative correlations).

Cross-correlation information is limited because waveforms are not available for every phase at each station-event pair; therefore, we use a combination of catalog and crosscorrelation data. When using a combination of data, we performed four sets of five iterations. The first two sets are weighted so that the catalog information is strongly weighted: 1 for catalog $P$-wave, 0.5 for catalog $S$-wave, and 0.01 for cross-correlated phases. The second two are weighted so the cross-correlation information is strongly weighted: 1 for cross-correlated $P$ waves, 0.5 for crosscorrelated $S$ waves, 0.01 for catalog $P$ waves, and 0.005 for catalog $S$ waves. The reason for two iterations is that the majority of the cross-correlated data comes from Canadian stations, and this can skew the relocations (due to the restricted azimuthal coverage) if only cross-correlation data

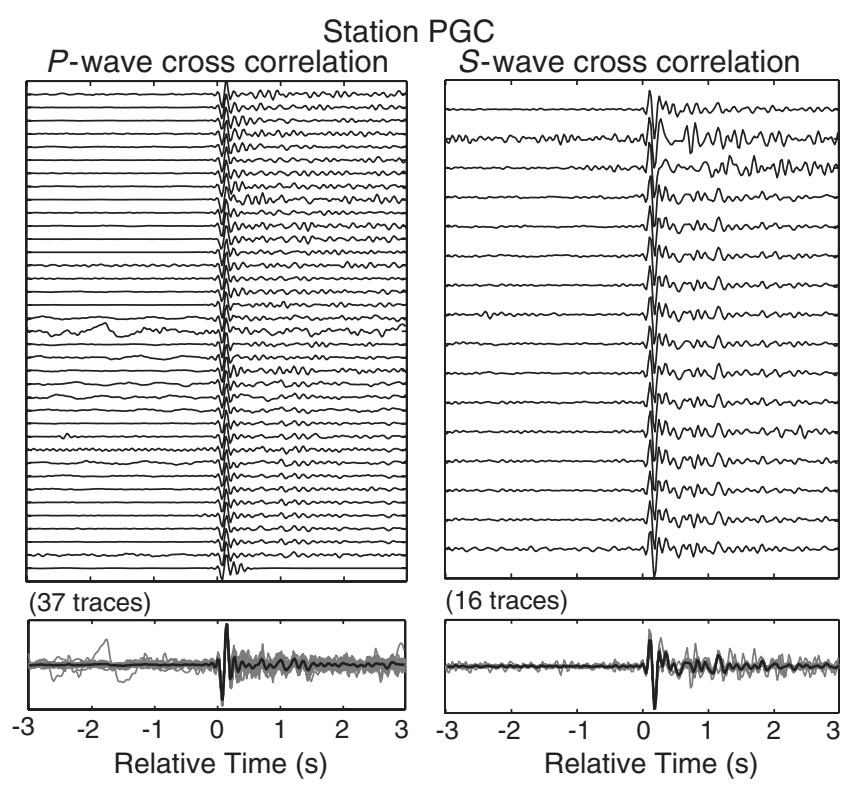

Figure 3. Example of cross-correlated waveforms recorded at station PGC. Each trace represents a $P$-wave (left) or $S$-wave (right) arrival for a different earthquake in the San Juan Island region. Stacked arrivals that have been corrected for lag are shown for each phase (bold trace, bottom). Note only highly correlated waveforms (correlation coefficient $>0.7$ ) are shown and used for double-difference relocation. These waveforms have been filtered between $1-10 \mathrm{~Hz}$, and the amplitude has been normalized. $P$ waves are shown are on the vertical component, and $S$ waves are on an east-oriented horizontal component. 
are used or if it is weighted heavily in the early set of iterations. By heavily weighting catalog locations first, the overall structure is determined; the finer-scale structure is determined by the cross-correlated data. We tested this thoroughly by using different weighting schemes, numbers of iterations, and combinations of data, such as only using cross-correlation data. This allows the large-scale features to be resolved by the catalog data and small-scale features to be resolved by the cross-correlated data (Waldhauser and Ellsworth, 2000; Waldhauser, 2001).

\section{Data}

As discussed earlier, two regions are chosen for investigation based on their relatively high rates of seismicity and proximity to urban centers: the Fraser River Valley and the San Juan Islands (Figs. 1 and 2). The Fraser River Valley and San Juan Islands datasets consist of 611 and 300 events, respectively. In both datasets, the earthquakes were recorded from 1992-2006 and range in magnitude from 0-3. This time period is used because an upgrade in the network in southwest British Columbia was made in 1992, providing real-time continuous data from mostly three-component broadband seismometers. To just consider earthquakes in the North American crust, we used a depth range of $0-40 \mathrm{~km}$ to select the events.

\section{Seismic Networks}

For maximum information from earthquakes in southwest British Columbia, we consider seismic stations in Canada and the United States. In Canada, we use permanent stations from the Canadian National Seismograph Network (CNSN) and arrays of temporary stations on Vancouver Island from the Portable Observatories for Lithospheric Analysis and Research Investigating Seismicity (POLARIS) consortium. In the United States, we use stations from the Pacific Northwest Seismic Network (PNSN), operated by the University of Washington.

\section{Standard Locations and Velocity Models}

All initial earthquake locations come from the CNSN catalog. Phase arrival information comes from both CNSN and University of Washington catalogs. Over the years, various single-event location algorithms have been used for these events. The two main algorithms used are LocEq (Geological Survey of Canada in-house software) and GENLOC. GENLOC is the more modern method used and is described by Pavlis et al. (2004). In the San Juan Islands study region, waveforms were necessary to pick $S$-wave arrivals from PNSN stations because only $P$-wave arrival information is sent to CNSN. The San Juan Island region required this information (more so than the Fraser River Valley region) because it relies on PNSN stations for $>180^{\circ}$ of azimuthal coverage. The $S$-wave picks were then incorporated into the database, and then all events were located with GENLOC.
In general, the Vel03 velocity model, shown in Figure 4 and described by Rogers (1983), is used for catalog locations for earthquakes in southwest British Columbia. However, the choice of velocity model is important for the earthquake locations to reduce artifacts due to sharp velocity contrasts at layer boundaries. Michelini and Lomax (2004) investigate the effect of choosing an incorrect velocity model when relocating events with hypoDD. Their study uses synthetic data from a known velocity model and earthquake locations and varies the model and station geometry when relocating the events. In comparing the relocations with the known locations, they found that some velocity models distorted the configuration of the events. They also observed that an incorrect velocity model in conjunction with certain sourcereceiver geometries can result in artifacts that appear as lineations. We investigate the effect of the velocity model on earthquake locations by considering alternative models specific to each region. For all velocity models we assume a $V_{P} / V_{S}$ ratio of 1.73 .

\section{Results}

\section{Fraser River Valley, British Columbia}

The Fraser River Valley region is just east of Vancouver and straddles the Canada-U.S. border (box 1 in Fig. 2). Catalog locations appear scattered with a few small clusters (Fig. 5). There are some surface expressions of faults, but

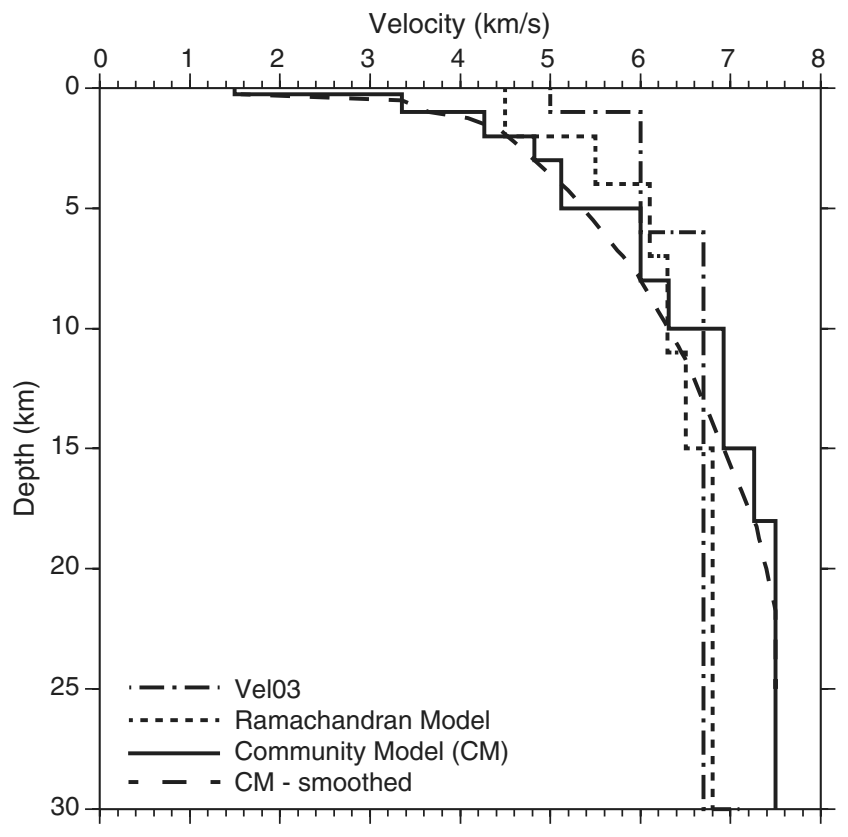

Figure 4. $P$-wave velocity models used for earthquake relocations in southwest British Columbia and the San Juan Islands. The original model for southwest British Columbia is shown as a dot-dashed line (Vel03). The Ramachandran model (Ramachandran et al., 2005), shown as a dotted line, is used for the San Juan Islands. The layered Community model used for the streak of seismicity in the Fraser River Valley, shown as a solid line, is based on a gradational model by Molnar (2011), which is shown as a smooth dashed line. 


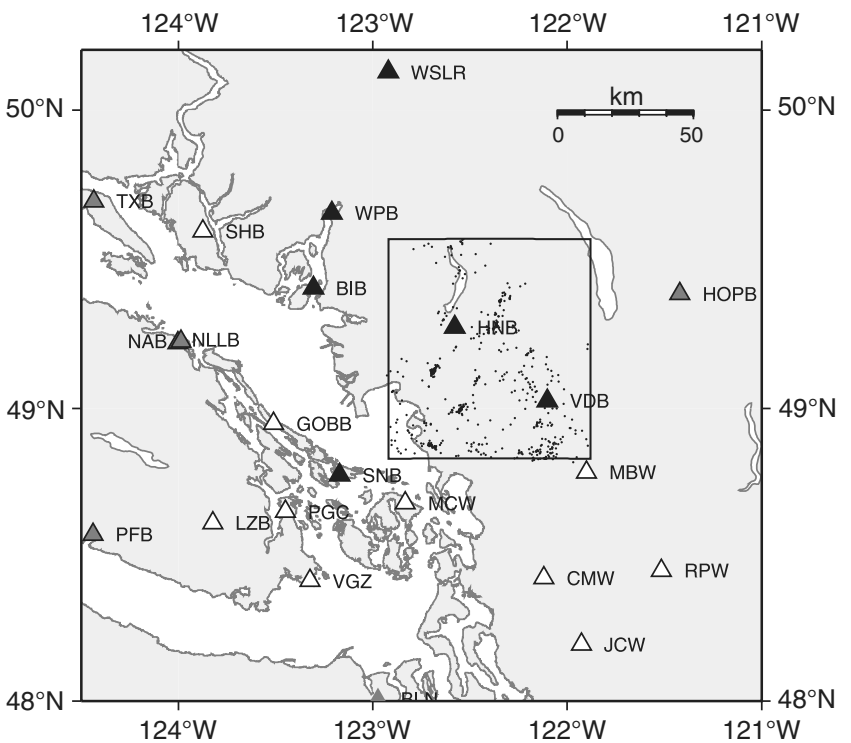

Figure 5. Seismicity for the Fraser River Valley in southwest British Columbia, 1992-2006. Hypocenters (black dots) were determined using hypoDD. Stations are shaded according to their contribution: black indicates a large number of phases used $(>100)$, white indicates a moderate number (20-100), and gray indicates a small number $(<20)$. Note that some stations used to relocate earthquakes are not shown as they are located outside the region of this map and only contribute a few arrivals. little is known about when they last ruptured in southwest British Columbia. Studies of faults in Washington have involved LiDAR to identify Holocene fault scarps and trenching to determine the ages of fault ruptures (Barnett, 2007). Older, unmapped faults may exist but could be covered by the sediments of the Fraser River delta.

Initially $\sim 600$ earthquakes over a $1^{\circ} \times 1^{\circ}$ square (box in Fig. 5) were relocated with hypoDD using the LSQR method. Events were small with $M_{\mathrm{L}}<3$. Detailed analysis was carried out on a subset of events using the SVD method to estimate uncertainties (box, Fig. 6). Catalog locations were used as starting estimates, and the velocity model was the standard 1D model Vel03 (Fig. 4). A total of 67,275 differential arrival times were used from both $P$ (35,625 arrivals) and $S$ waves (31,650 arrivals) observed at $\sim 70$ stations. We down-weight event pairs with separation distances $>5 \mathrm{~km}$ and with residuals of more than five times the standard deviation. A damping factor of 80 is applied to the solution.

The relocated hypocenters show improved clustering, with several of the clusters becoming more focused (Fig. 6). Error estimates are not shown for these results as they are not meaningful when hypoDD is used in LSQR mode. The apparent concentration of seismicity in the top $6 \mathrm{~km}$ could be due to a jump in the velocity model from 6 to $6.7 \mathrm{~km} / \mathrm{s}$. The depth extent of the seismicity appears to be shallow to
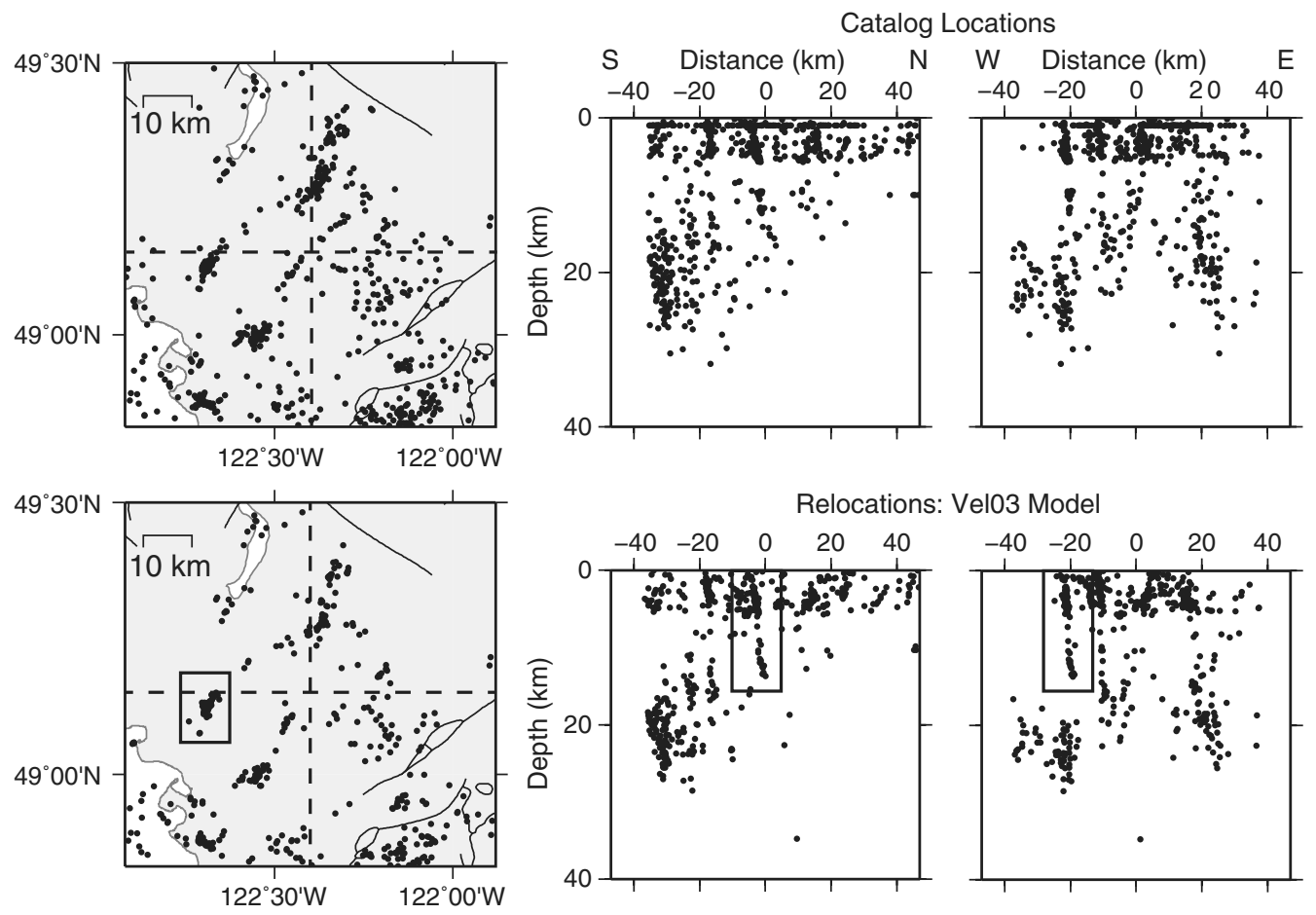

Figure 6. Double-difference relocations for the Fraser River Valley region shown in Figure 5. The upper row shows standard catalog locations, and the bottom row shows events relocated using hypoDD. Uncertainties are not shown because the LSQR method was used. Dashed lines indicate the profiles of the cross sections, where zero is the point at which the profiles cross. The boxes outline the subset of events selected for more detailed analysis. The thin black lines indicate mapped surface faults. 
the north, and there is a large cluster of seismicity $\sim 20 \mathrm{~km}$ deep, $\sim 40 \mathrm{~km}$ south, and $\sim 20 \mathrm{~km}$ east (see cross sections in Fig. 6). We can identify at least two lineations that dip to the northeast and extend from the surface to $\sim 15 \mathrm{~km}$ depth. The lineations do not appear to extend along strike and could be described as streaks of seismicity.

Figure 7 shows the subset of 84 events belonging to the seismicity streak outlined by the box in Figure 6 . These events are relocated using hypoDD with SVD using catalog differential arrival times. The events are well observed with 3673 differential $P$-wave times and 4068 differential $S$-wave times. The subset of events was relocated with both the standard Vel03 velocity model and a more detailed velocity mod- el from Molnar (2011). This model, which we refer to as the Community model, includes low-velocity near-surface layers related to the Fraser River delta sediments. The initial locations show two clusters that appear to be offset from each other in depth. The relocation processing also identifies two distinct clusters and relocates events within each cluster separately. Initial weighting parameters used in the first set of iterations are the same as discussed in the section DoubleDifference Relocation; however, in the second set we down-weight events separated by $>8 \mathrm{~km}$ and arrival data with residuals $>5$ times the standard deviation. We compare the relocation results obtained from using the two different velocity models (Fig. 7). Our goal was to determine if the
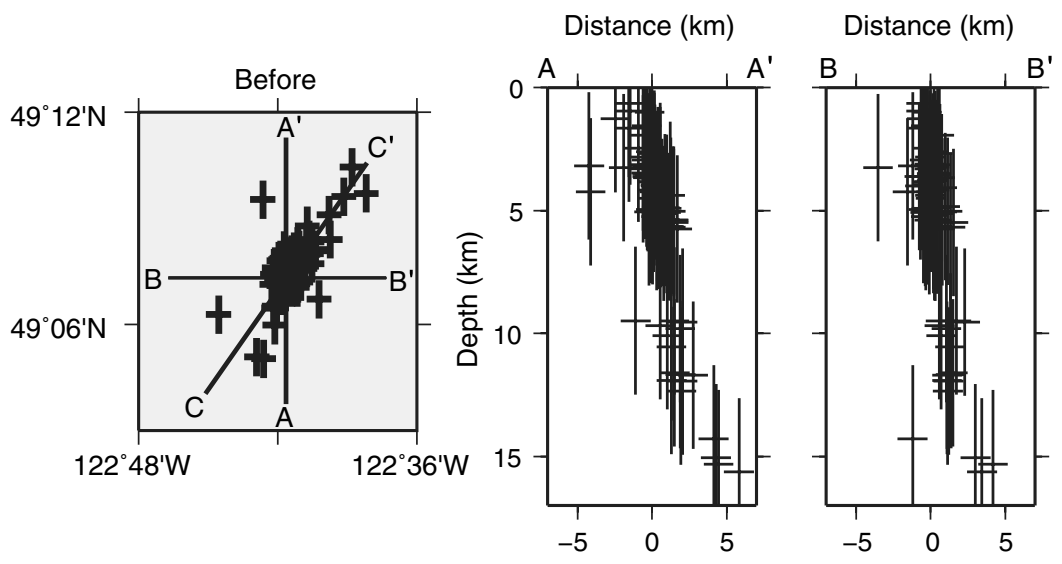

Distance $(\mathrm{km})$
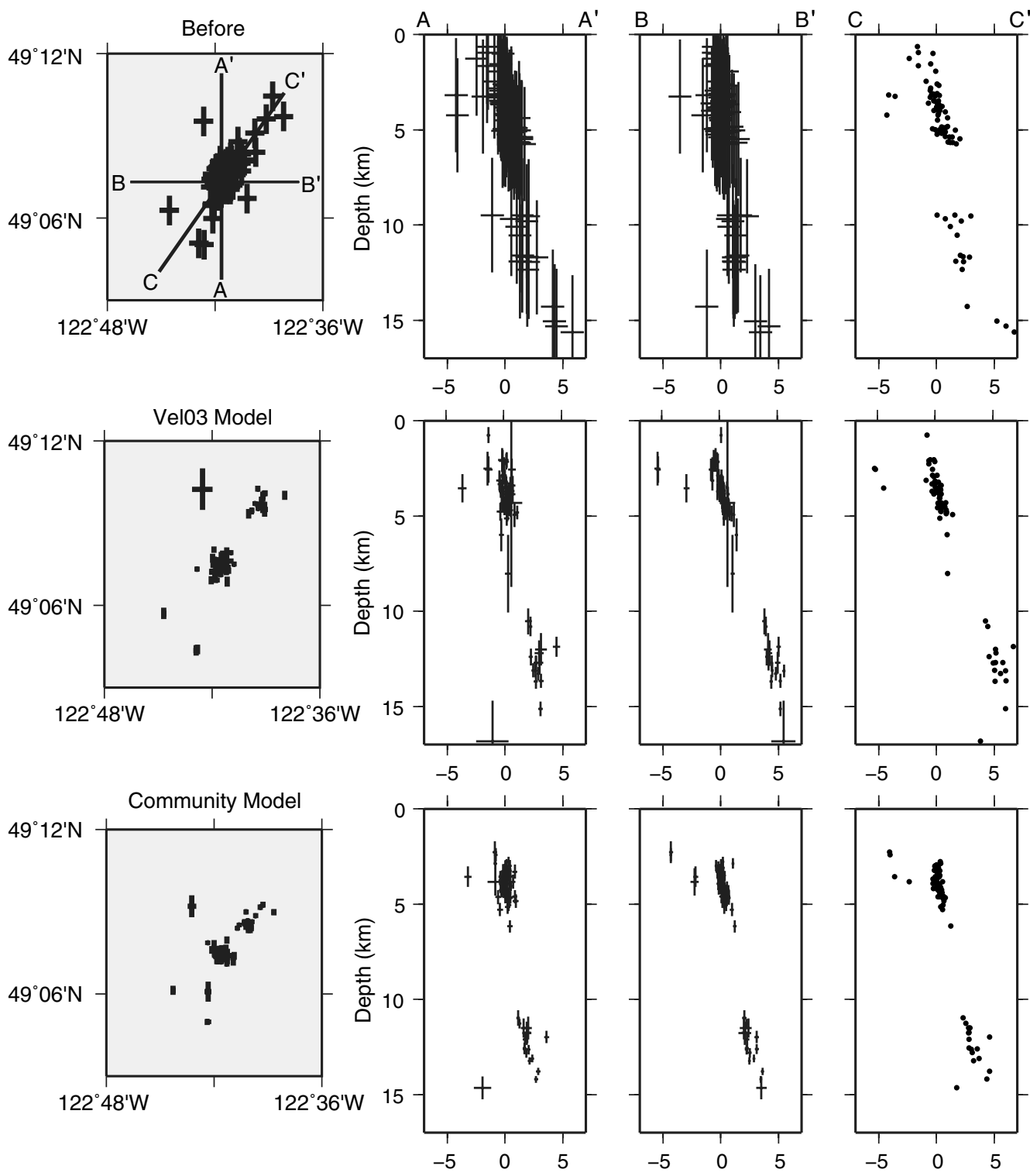

Figure 7. Double-difference relocations of a cluster of 84 events (box, Fig. 6). Locations and estimated uncertainties of earthquakes computed using a standard catalog routine (upper row) and those computed using hypoDD with the Vel03 (middle row) and Community (lower row) velocity models. The origin of the cross-section axes is the point where the profiles intersect. Precise relocation resolves two clusters on a $45^{\circ} \mathrm{NE}$-dipping structure. 
two clusters of seismicity are separated or if the gap between clusters is an artifact of the velocity model. Comparing results from relocations with the two velocity models in Figure 7 (second and third rows), the two clusters remain separated; therefore, either there is a gap in seismicity along a single structure or the seismicity occurs clustered on separate structures. Further, Figure 7 shows that using a more representative velocity model significantly reduced location error particularly for events with large vertical errors. We also tested the dependence of the relocations on the starting model by giving each event the same starting location (approximately the center of the streak). We found that the dimensions of the streak were not dependent on the starting model; however, the size of the gap between the two clusters was reduced from $\sim 5 \mathrm{~km}$ to $\sim 2 \mathrm{~km}$ with different initial locations. This suggests care is needed when interpreting small gaps in seismicity and that the dependence on the starting model is a source of error not included in the standard uncertainty estimates.

This small dataset can be used to evaluate errors in relocating events because SVD was applied. Figure 7 shows a general estimate of the error in the catalog locations of $\sim 1 \mathrm{~km}$ in the horizontal and $\sim 2 \mathrm{~km}$ in the vertical. The relative mean error after relocating with catalog data and using the Vel03 velocity model are $\sim 200 \mathrm{~m}$ (horizontal) and $540 \mathrm{~m}$ (vertical). Using the Community model, the errors are reduced to $\sim 180 \mathrm{~m}$ (horizontal) and $340 \mathrm{~m}$ (vertical). These results suggest that using a more accurate velocity model that accounts for the low-velocity surface layers improves the vertical location accuracy by a factor of 1.6.

\section{San Juan Islands, Washington}

The San Juan Islands have been an area of persistent crustal seismicity throughout the duration of earthquake monitoring in British Columbia. The largest magnitude event in the catalog is $M_{\mathrm{L}} \sim 3.0$; however, magnitude 5.5-6 events occurred at unknown depths in 1920 and 1909 (G. Rogers, personal comm., 2008; Lamontagne et al., 2008). We relocated 300 earthquakes that occurred from 1992-2008 over a $20 \mathrm{~km} \times 20 \mathrm{~km}$ area. Figure 8 shows the location of the San Juan Islands and the combination of CNSN and PNSN stations used for earthquake relocations. These provide a reasonable azimuthal coverage of the seismicity; however, not all stations were installed and operating during the entire study period, so station coverage and station-event pairs are variable.

Before earthquakes were relocated with doubledifference methods, we located each event with the singleevent location program GENLOC (Pavlis et al., 2004). The purpose of this was to produce a consistent dataset and representation of errors, making sure all starting locations were determined with the same algorithm and velocity model. We also repicked some of the $S$ waves for cases in which a converted phase arriving before the $S$ wave had been picked by mistake. The LSQR method in hypoDD is used for the

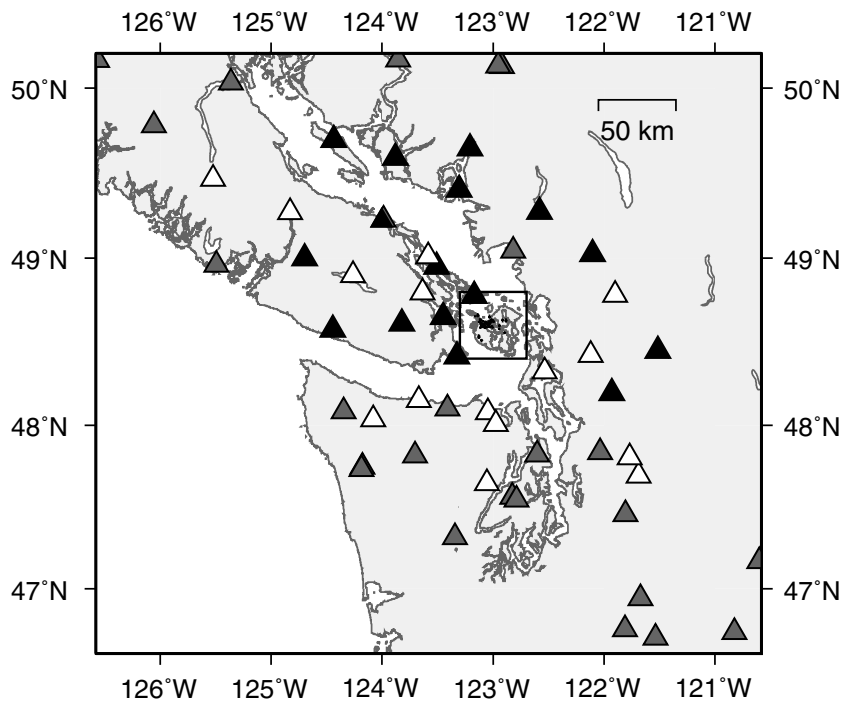

Figure 8. Stations used for double-difference relocation for earthquakes in the San Juan Islands (boxed region). Stations are shaded according to their contribution: black indicates a large number of phases used $(>100)$, white indicates a moderate number $(20-100)$, and gray indicates a small number $(<20)$.

relocation because there are over 100 events, so the error estimates are not reliable. Approximately 23,000 catalog $P$ and 22,500 catalog $S$ differential travel times were used. The first iteration used parameters described in the section Double-Difference Relocation, while the second iteration used a damping parameter of 80 , down-weighted events with separation distances of $>10 \mathrm{~km}$, and down-weighted arrival times with residuals over six times the standard deviation.

After the events were relocated, the majority of the seismicity lay in two clusters that appear to be parallel to each out in the east-west B- $\mathrm{B}^{\prime}$ cross-section in Figure 9. The majority of the seismicity lies between 10 and $25 \mathrm{~km}$ deep.

While simple velocity models may be satisfactory for preliminary earthquake locations, more care is needed to interpret seismicity and relate it to structure. Relocations for data from the San Juan Islands using Vel03 model were found to cause artifacts with many events separated into layers due to the large jumps in the velocity model (Fig. 4). The model can be improved by increasing the number of layers, thereby decreasing the thickness of each layer and the velocity contrast between layers. We constructed a finer velocity model based on the results from a tomographic study by Ramachandran et al. (2005) (Fig. 4). Figure 9 shows relocation results using the two different velocity models. With the Ramachandran model (third row of Fig. 9), the earthquake hypocenters do not locate preferentially within certain layers but appear distributed across layer boundaries.

We also cross-correlated waveforms in the San Juan Islands to get precise differential arrival times for relocation, using $7308 P$-wave and $4385 S$-wave arrivals observed at 30 stations. However, many of these stations were not deployed 

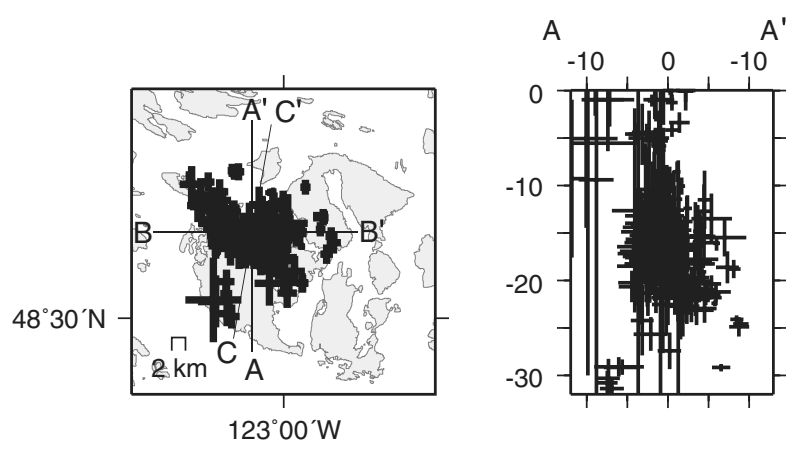

Original Locations

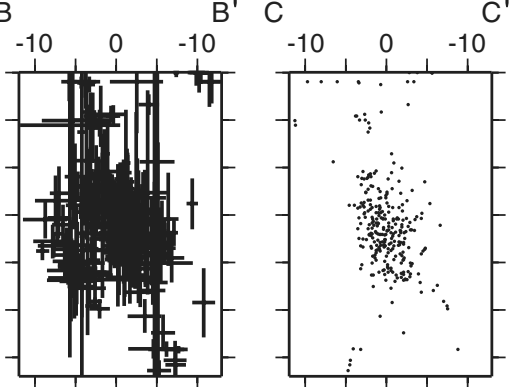

Relocated CAT Vel03
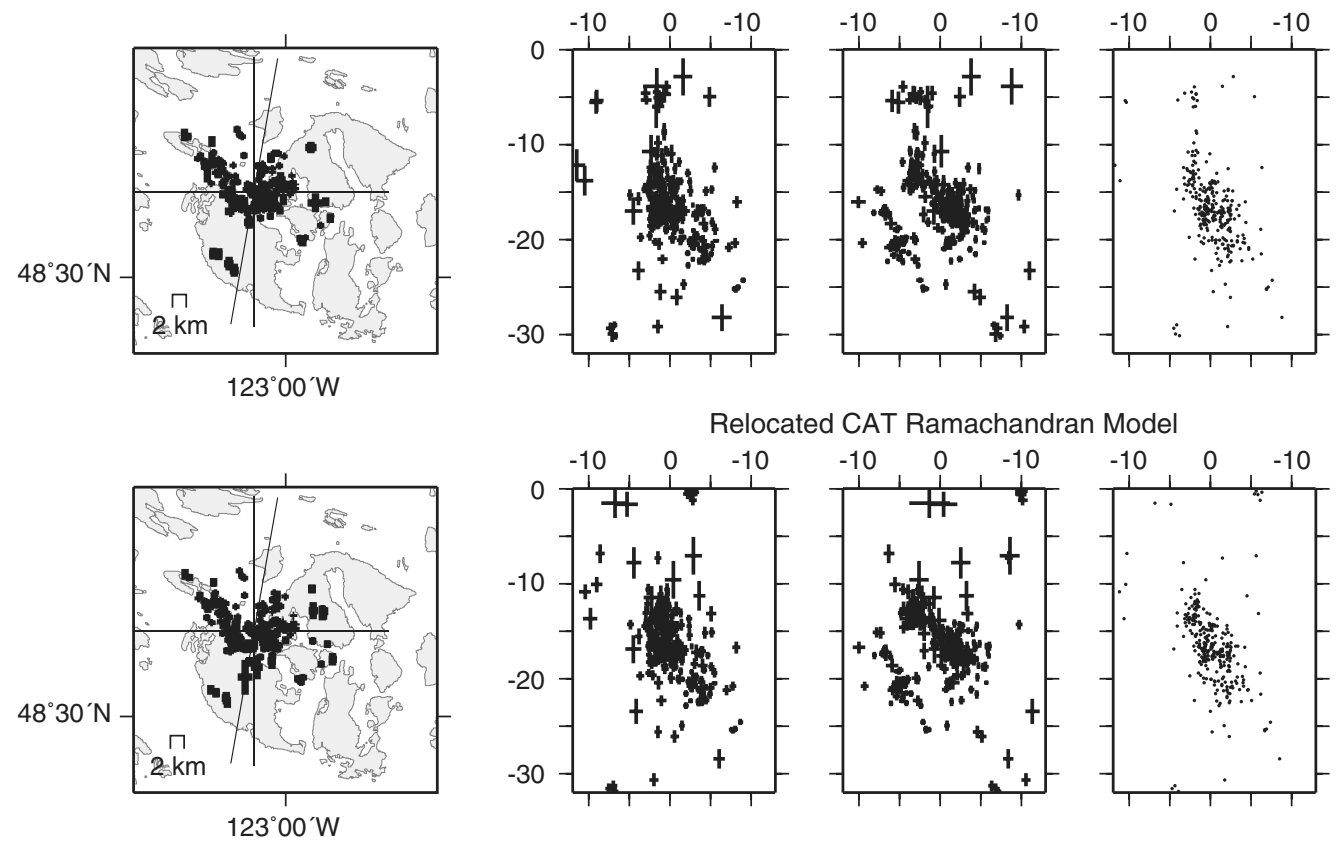

Relocated CAT+CC Ramachandran Model
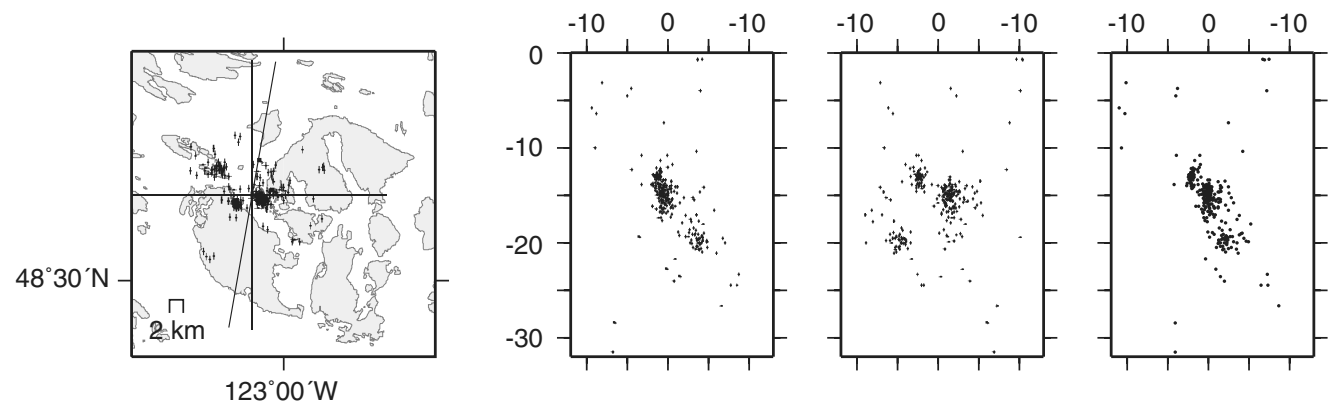

Figure 9. (Left) Map and (middle and right) cross sections of earthquake locations and estimated uncertainties near San Juan Islands. The first (top) row shows the original locations from the CNSN catalog. The second row shows events relocated using hypoDD with the standard Vel03 velocity model and catalog (CAT) differential arrival times. The third row shows relocated events using the Ramachandran velocity model and catalog arrival data. The fourth row (bottom) shows relocated events using the new velocity model and both catalog and crosscorrelated (CC) waveform data.

for the duration of the study and contribute only a small number of cross-correlation observations suitable for use in hypoDD. The closest stations (PGC, SNB, and GOBB) each contributed several thousand cross-correlated differential arrival times. In total, 28,049 $P$-wave and $9055 S$-wave differential arrival times meet the acceptance criteria after cross-correlation for relocating earthquakes in the San Juan
Islands. The results from combining cross-correlation $(\sim 37,000$ differential arrival times) and catalog data ( $\sim 37,000$ differential arrival times) and using the Ramachandran model are shown in Figure 9 (bottom row). This process relocated 277 out of the original 312 events. When crosscorrelation data are added, the earthquakes within the dipping structures appear tightly clustered into three groups. 
We rotate the projection to define the plane where the groups align, assuming they all lie on the same structure. We determine a maximum alignment in depth along cross-section $\mathrm{C}-\mathrm{C}^{\prime}$ (Fig. 9), suggesting this structure is dipping $\sim \mathrm{N} 20^{\circ} \mathrm{E}$ with a plunge of $60^{\circ}$ and strike of $\sim 290^{\circ}$. A different interpretation might have been made if only catalog data were considered, as only two groups are resolved (Fig. 9, middle rows). The interpretation of an east-west-striking structure is similar to the strike of nearby mapped faults and therefore is the preferred interpretation (discussed further in the section Related Focal Mechanisms and Fault Data). The clustered nature of the earthquake locations along the structure may be related to patches of slip due to heterogeneity, such as could be caused by stress concentrations due to asperities or changes in rheology (Waldhauser et al., 2004).

A subset of 50 events from San Juan Island data are used to get reasonable error estimates. This subset includes both cross-correlated and catalog differential arrival times with events selected to provide maximum information based on the following parameters: number of observations $>10$, magnitude $M_{\mathrm{L}} \geq 1$, and the origin time after 1996 (because more waveform data were available). The original earthquake hypocenters have mean horizontal error of $\sim 900 \mathrm{~m}$ and vertical error of $\sim 1500 \mathrm{~m}$. After relocating the events with only catalog differential arrival times, the mean errors were reduced to $\sim 500 \mathrm{~m}$ (horizontal) and $\sim 1100 \mathrm{~m}$ (vertical). When cross-correlation differential times were included, the mean errors were further reduced to $\sim 130 \mathrm{~m}$ (horizontal) and $\sim 190 \mathrm{~m}$ (vertical). In summary, doubledifference relocation using catalog data reduced the errors by a factor of 2 in the horizontal and 1.4 in the vertical, but including cross-correlation data reduces the error further by a factor of 4 (horizontal) and 10 (vertical).

\section{Related Focal Mechanisms and Fault Data}

Other datasets can provide supporting information about the seismic activity of faults in an area. We compare our earthquake relocation results from the San Juan Islands with focal mechanisms and fault data from seismic reflection and multibeam bathymetric surveys. Focal mechanisms from Balfour et al. (2011) and Mulder (1995) are shown in Figure 10, along with the earthquake relocations discussed in the section San Juan Islands, Washington. Many of the focal mechanisms in this group have a nodal plane (potential fault plane) oriented approximately east-west, which agrees with the strike of the seismicity. Only a few focal mechanisms are directly related to the relocated seismicity because the magnitudes of the relocated events are too small to observe enough first motions to determine a focal mechanism. The few that are related have variable nodal plane orientations and sense of slip and therefore contribute little information about the possible rupture plane. These focal mechanisms are mostly a mix of strike-slip and thrust faulting, which is characteristic of crustal seismicity in the larger region (Balfour et al., 2011). Principle stress orientations and

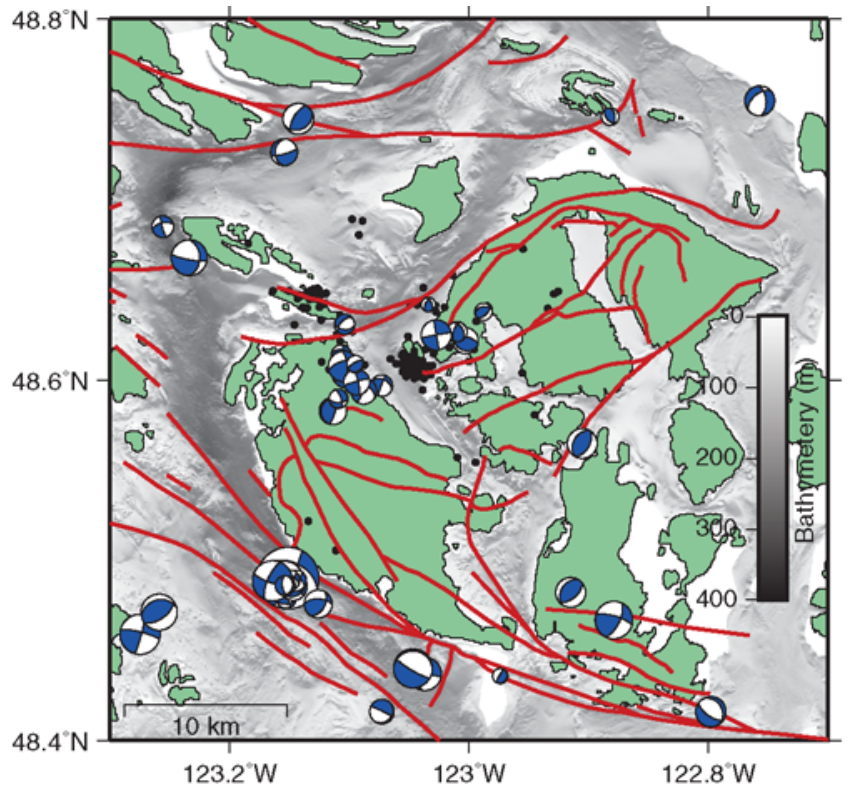

Figure 10. Comparison of earthquake relocations (black dots) in the San Juan Islands with focal mechanisms (Mulder 1995; Balfour et al., 2011), recently mapped faults (bold lines) and multibeam bathymetry data (V. Barrie, personal comm. 2011). The color version of this figure is available only in the electronic edition.

the stress ratio were determined from this group of focal mechanisms by Balfour et al. (2011). The maximum horizontal compressive stress direction $\left(117^{\circ} \pm 23^{\circ}\right)$ is approximately parallel to the strike of the seismicity; however, stress results from surrounding groups of mechanisms suggest that it might be more oblique. The faulting regime supported by the focal mechanisms and stress inversion is oblique-reverse faulting.

Geological mapping of the San Juan Islands by Brandon (1989) suggests that structures are related to the Late Cretaceous thrust sheets. A number of interpretations have been applied to these faults (Brandon, 1989; Maekawa and Brown, 1991), but, in general, they do not agree with the northward-dipping seismicity we observe from the earthquake relocations. Recent studies involving seismic reflection and multibeam bathymetric surveys consider disturbances and structures on the seafloor that might indicate active faults (V. Barrie, personal comm., 2011). These recently identified features are combined with detailed field mapping to update the fault map for the San Juan Island to include offshore features (Fig. 10). Because of the lack of seismicity in the top $10 \mathrm{~km}$ of the crust and the complicated behavior of faults near the surface, it is difficult to project the structure outlined by seismicity to the surface and then associate it with any specific fault. However, the east-west strike of the seismicity is similar to the strike of recently mapped faults both north and south of the San Juan Islands, as well as other major faults in the region (such as the Tacoma fault [Sherrod et al., 2004], Devils Mountain fault [Johnson et al., 2001], and Seattle fault [Blakely et al., 2002]). 
Less evidence is available to support recent faulting in the Fraser River Valley of southwest British Columbia. Pullan et al. (1998) investigated the structure of the Fraser River delta using seismic reflection surveys and found only one or two instances where disturbed strata could indicate faulting. There are a few well-exposed faults in this region: the Sumas Mountain fault, Vedder fault, Boulder Creek fault, and Kendall fault scarp (Barnett, 2007). These faults are all located in the southeast of the study region and trend southwest-northeast, in the same direction as the streaks of seismicity described in the section on the Fraser River Valley, British Columbia. While there appear to be high levels of seismicity beneath the Vedder fault, our relocations did not reveal any structure within the seismicity. Where we observe streaks of seismicity, there is little evidence of faulting near the surface. This could suggest that whatever faulting occurs beneath the delta does not disturb the overlying sediments in a well-preserved manner or that faulting occurs deep in the crust and rarely offsets near-surface sediments.

\section{Discussion and Conclusions}

We relocated earthquakes in southwest British Columbia and beneath the San Juan Islands, Washington, using catalog and waveform differential arrival times. These precise relative earthquake locations help illuminate seismically active structures and relate them to recently mapped surface faults. Historically, magnitude 6-7 earthquakes occur in the North American crust in this region, but it is difficult to determine the structures on which these events occurred and where they may occur in the future.

We used various velocity models for our relocations and observed that more detailed models reduced the vertical relocation errors and removed artifacts caused by large velocity contrasts at layer boundaries. A subset of data from each region was selected to relocate via SVD in order to quantify the relocation errors. On average, errors in catalog locations are $1000 \mathrm{~m}$ in the horizontal and $2000 \mathrm{~m}$ in the vertical. Doubledifference relocation using catalog data reduces errors by at least a factor of 1.4; if both cross-correlation and catalog data are used, errors are reduced to $\sim 100 \mathrm{~m}$ in the horizontal and $\sim 200 \mathrm{~m}$ in the vertical.

This study identifies an active structure beneath the San Juan Islands that strikes $\sim 290^{\circ}$ and dips northward $\left(\mathrm{N} 20^{\circ} \mathrm{E}\right)$ at an angle of $60^{\circ}$. The east-west strike of the structure is similar to those of recently mapped surface faults; however, no shallow seismicity $(<10 \mathrm{~km})$ has been observed, so it cannot be associated with a specific fault. Some focal mechanism nodal planes also support an east-west strike fault with a steep dip. The focal mechanisms and stress inversion results suggest an oblique-reverse faulting regime. This structure may also coincide with the location of a magnitude $M_{\mathrm{L}} 6$ earthquake in 1909 and magnitude $M_{\mathrm{L}} 5.5$ in 1920, although the location and depth of these events are not well known. The inclusion of waveform cross-correlation data was vital for the correct interpretation of this data; with- out it, the structure could be interpreted as two east-dipping faults.

Seismicity in the Fraser River Valley of British Columbia is less well defined but contains several narrow streaks of seismicity extending from the surface to $\sim 20 \mathrm{~km}$ depth. Similar streaks have been observed near the San Andreas fault and attributed to changes in rheology or stress concentrations between locked and creeping portions of the fault (Waldhauser et al., 2004).

This study has shown that precise earthquake relocations can provide insight into structures that are otherwise hidden and seismicity that does not correlate with surface faulting. The observed seismicity cluster might be associated with different patches of fault slip; and, with the incorporation of more historical events and continued monitoring, this approach could illuminate the full extent of the structure.

\section{Data and Resources}

Waveform and catalog arrival times from permanent and temporary stations were obtained directly from the CNSN and POLARIS. The facilities of the Incorporated Research Institutions for Seismology (IRIS) Data Management System (DMS), and specifically the IRIS Data Management Center, were used for access to additional waveform and metadata required in this study. The IRIS DMS is funded through the GEO Directorate of the National Science Foundation through their Instrumentation and Facilities Program under Cooperative Agreement EAR-0552316. Antelope software (http://www.brtt.com/software.html, last accessed December 2010), developed by Boulder Real Time Technologies, was used for seismic analysis and to manage data. The antelope toolbox for MATLAB (www.mathworks.com/products/ matlab, last accessed February 2011) by Kent Lindquist and GISMO (http://www.giseis.alaska.edu/Seis/EQ/tools/ GISMO/, last accessed February 2011) by Celso Reyes, Michael West, and contributing authors was used in crosscorrelating waveform data.

\section{Acknowledgments}

We would like to thank Kent Lindquist and Felix Waldhauser for advice in using their programs; the employees of Natural Resources Canada who maintain the Canadian National Seismograph Network (CNSN catalog and waveform archive) and who provided technical support; Vaughn Barrie for providing the latest faults maps; and Garry Rogers for helpful discussions. Natural Sciences and Engineering Research Council (NSERC) Discovery Grants provided funding for this project. This article is Geological Survey of Canada Contribution number 20110032.

\section{References}

Balfour, N. J., J. F. Cassidy, S. E. Dosso, and S. Mazzotti (2011). Mapping crustal stress and strain in southwest British Columbia, J. Geophys. Res. 116, no. B03314, doi 10.1029/2010JB008003.

Barnett, E. (2007). Active faulting at the northeast margin of the greater Puget Lowland: A paleoseismic and magnetic-anomaly study of the Kendall fault scarp, Whatcom County, northwest Washington, M.Sc. Thesis, Humbolt State University, California. 
Blakely, R. J., R. E. Wells, C. S. Weaver, and S. Y. Johnson (2002). Location, structure, and seismicity of the Seattle fault zone, Washington: Evidence from aeromagnetic anomalies, geologic mapping, and seismic-reflection data, Geol. Soc. Am. Bull. 114, 169-177.

Brandon, M. T. (1989). Geology of the San Juan-Cascade nappes, northwestern Cascade Range and San Juan Islands, in N. L. Joseph et al. (Editors), Geologic Guidebook for Washington and Adjacent Areas: Washington Division of Geology and Earth Resources Information Circular 86, Washington State Department of Natural Resources, Olympia, Washington, 137-162.

Cassidy, J. F., G. Rogers, and F. Waldhauser (2000). Characterization of active faulting beneath the Strait of Georgia, British Columbia, Bull. Seismol. Soc. Am. 90, 1188-1199.

Clowes, R., M. Brandon, A. Green, C. Yorath, A. Brown, E. Kanasewich, and C. Spencer (1987). Lithoprobe-southern Vancouver Island: Cenozoic subduction complex imaged by deep seismic reflections, Can. J. Earth Sci. 24, 31-51.

Hauksson, E., and P. Shearer (2005). Southern California hypocenter relocation with waveform cross-correlation, part 1: Results using the double-difference method, Bull. Seismol. Soc. Am. 95, 896-903.

Johnson, S. Y., S. V. Dadisman, D. C. Mosher, R. J. Blakely, and J. R. Childs (2001). Active tectonics of the Devils Mountain fault and related structures, northern Puget Lowland and eastern Strait of Juan de Fuca region Pacific Northwest, U. S. Geol. Surv. Profess. Pap. 1044-9612 1-45.

Journeay, J. M., and S. P. Williams (1995). Tectonic assemblage of the Canadian Cordillera, Geol. Surv. Canada Open File 2948, 19 pp.

Lamontagne, M., S. Halchuk, J. Cassidy, and G. Rogers (2008). Significant Canadian earthquakes of the period 1600-2006, Seismol. Res. Lett. 79, 211-223, doi 10.1785/gssrl.79.2.211.

Maekawa, H., and E. H. Brown (1991). Kinematic analysis of the San Juan thrust system, Washington, Geol. Soc. Am. Bull. 103, 1007-1016.

McCrory, P. A., J. L. Blair, D. H. Oppenheimer, and S. R. Walter (2004). Depth to the Juan de Fuca slab beneath the Cascadia subduction margin: A 3-D model for sorting earthquakes, U. S. Geol. Surv. Data Series DS-91 (available on CD-ROM).

Michelini, A., and A. Lomax (2004). The effect of velocity structure errors on double-difference earthquake location, Geophys. Res. Lett. 31, doi 10.1029/2004GL019682.

Molnar, S. (2011). Predicting earthquake ground shaking due to 1-D soil layering and 3-D basin structure in southwest British Columbia, Canada, Ph.D. Thesis, University of Victoria, British Columbia, Canada.

Monger, J., R. Price, and D. Tempelman-Kluit (1982). Tectonic accretion and the origin of the two major metamorphic and plutonic welts in the Canadian Cordillera, Geology 10, 70-75.

Mulder, T. (1995). Small earthquakes in southwestern British Columbia (1975-1991), Ph.D. Thesis, University of Victoria, British Columbia, Canada.

Paige, C., and M. Saunders (1982a). LSQR: An algorithm for sparse linear equations and sparse least squares, ACM Trans. Math. Software 8, 43-71.

Paige, C., and M. Saunders (1982b). Algorithm 583: LSQR: Sparse linear equations and least squares problems, ACM Trans. Math. Software $\mathbf{8}$, 195-209.
Pavlis, G., F. Vernon, D. Harvey, and D. Quinlan (2004). The generalized earthquake-location (GENLOC) package: An earthquake-location library, Comput. Geosci. 30, 1079-1091.

Pullan, S. E., J. A. Hunter, H. M. Jol, M. C. Roberts, R. A. Burns, and J. B. Harris (1998). Seismostratigraphic investigations of the southern Fraser River delta, in Geology and Natural Hazards of the Fraser River Delta British Columbia, J. J. Clague, J. L. Luternauer, and D. C. Mosher (Editors), Geol. Surv. Canada Bull.525, 91-122.

Ramachandran, K., S. E. Dosso, C. Zelt, G. Spence, R. Hyndman, and T. Brocher (2004). Upper crustal structure of southwestern British Columbia from the 1998 seismic hazards investigation in Puget Sound, J. Geophys. Res. 109, no. B09303, doi 10.1029/2003JB002826.

Ramachandran, K., S. E. Dosso, G. Spence, R. Hyndman, and T. Brocher (2005). Forearc structure beneath southwestern British Columbia: A three-dimensional tomographic velocity model, J. Geophys. Res. 110, no. B02303, doi 10.1029/2004JB003258.

Riddihough, R. (1984). Recent movements of the Juan de Fuca plate system, J. Geophys. Res. 89, no. B8 6980-6994.

Ristau, J., G. Rogers, and J. Cassidy (2007). Stress in western Canada from regional moment tensor analysis, Can. J. Earth Sci. 44, 127-148, doi 10.1139/E06-057.

Rogers, G. (1983). Seismotectonics of British Columbia, Ph.D. Thesis, University of British Columbia, Vancouver, British Columbia, Canada.

Rogers, G., and H. Hasegawa (1978). A second look at the British Columbia earthquake of June 23, 1946, Bull. Seismol. Soc. Am. 68, 653-675.

Sherrod, B. L., T. M. Brocher, C. S. Weaver, R. C. Bucknam, R. J. Blakely, H. M. Kelsey, A. R. Nelson, and R. Haugerud (2004). Holocene fault scarps near Tacoma, Washington, USA, Geology 32, 9-12.

Waldhauser, F. (2001). hypoDD - a program to compute double-difference hypocenter locations, U. S. Geol. Surv. Open File Rept. 01-113, 25 pp.

Waldhauser, F., and W. Ellsworth (2000). A double-difference earthquake location algorithm: Method and application to the northern Hayward fault California, Bull. Seismol. Soc. Am. 90, 1353-1368.

Waldhauser, F., W. Ellsworth, D. Schaff, and A. Cole (2004). Streaks, multiplets, and holes: High-resolution spatio-temporal behaviour of Parkfield seismicity, Geophys. Res. Lett. 31, L18608, doi 10.1029/ 2004GL020649.

School of Earth and Ocean Sciences

Bob Wright Centre A405

University of Victoria

PO Box 3065 STN CSC

Victoria, British Columbia

Canada V8W 3V6

(N.J.B., S.E.D.)

Pacific Geoscience Centre

Geological Survey of Canada

P.O. Box 6000

Sidney, British Columbia

Canada V8L 4B2

(J.F.C.)

Manuscript received 22 February 2011 